\title{
A "CRISE HÍDRICA" NO SUDESTE DO BRASIL: ASPECTOS CLIMÁTICOS E REPERCUSSÕES AMBIENTAIS
}

The "water crisis" in southeastern Brazil: climatic aspects and environmental impacts.

Carlos Henrique Jardim

Universidade Federal de Minas Gerais

dxhenrique@gmail.com

Artigo recebido em 19/05/2015 e aceito para publicação em 09/12/2015

DOI: DOI: $10.12957 /$ tamoios.2015.16517

Resumo Este artigo analisa o impacto causado pela "crise hídrica" no sudeste do Brasil, incluindo aspectos da dinâmica natural do clima e repercussões ambientais. As fontes de informação que abordam o assunto incluíram livros, artigos, textos multimídia e dados meteorológicos oriundos de agências oficiais de governo. O escopo da análise recaiu sobre a relação sociedade-natureza a partir de óptica sistêmica e os resultados evidenciaram diferentes graus de comprometimento entre fatores naturais e sociais, assim como a necessidade de adoção de planejamento de médio e longo prazo para as ações governamentais.

Palavras-chave: clima; recursos hídricos; sociedade.

Abstract This paper analyzes aspects of the causes and consequences of the "water crisis" in southeastern Brazil. Information sources include books, articles, texts and multimedia data from official government agencies. The scope of the analysis fell on the society-nature relationship from systemic perspective. The results showed different degrees of commitment between natural and social factors, as well as the need to adopt the planning of medium and long term in government actions.

Keywords: climate; water resources; society. 


\section{INTRODUÇÃO}

Não é de hoje que se atribui ao clima a responsabilidade por crises econômicas, derrotas em batalhas, desaparecimento de civilizações e até mesmo a determinação do perfil psicológico de pessoas bem como o atraso e/ou avanço cultural de povos inteiros. Embora não seja o único fator, algumas dessas atribuições possuem justificativas coerentes com base em estudos e documentos histórico-arqueológicos (ACOT, 2005; DIAMOND, 2005; FAGAN, 2009). Outras, porém, são completamente infundadas como as questões sobre as mudanças climáticas globais e a (suposta) participação humana nesse processo.

A atual "crise hídrica" que teria afetado o sudeste brasileiro durante o ano de 2014 se encaixa nesse último contexto, a partir do qual foi colocado lado a lado e de forma dicotomizada tanto o papel do clima quanto da ação humana sobre o ambiente no desencadeamento desse processo, quando, na verdade, verificou-se a participação desses dois fatores. Este artigo tem o propósito de ponderar esses dois pontos de vista.

É inegável o papel do clima sobre a organização dos ambientes terrestres e as formas de vida. De acordo com Diamond (2005) o declínio da civilização Maia ocorreu após a sucessão de alguns anos com totais de chuvas abaixo da média. O autor cita em seu livro "Colapso" que a geologia calcária da península de Yucatán no atual México e antigo território Maia, deu origem a aqüíferos, na forma de dolinas e canais subterrâneos, extremamente susceptíveis às variações da chuva. A dependência desse povo em relação à agricultura e, portanto, da água para irrigação extraída dessas fontes, tornava-os, também, susceptíveis às variações no regime de chuvas.

Nestas circunstâncias, mesmo que a localização do território Maia em região tropical úmida/semi-úmida em latitudes de $15^{\circ}$ e $20^{\circ} \mathrm{N}$ (aprox.) favoreça a ocorrência de condições climáticas com elevados totais de chuvas no decorrer do ano, bastam alguns anos com totais de chuva abaixo da média para que os sistemas ambientais e sociais daquela região entrem em colapso. Efeito similar de períodos de secas de menor amplitude pode ser constatado através de vasta documentação referente aos impactos do El Niño de 1982-83 e 1997-98 (BERLATO e FONTANA, 2003) e em recente episódio de seca na Amazônia no ano de 2005 (COELHO et al., 2013). Diferentemente das savanas, domínios e ecossistemas florestais úmidos como os da Amazônia não resistem à sucessão de alguns meses de seca (o que dizer de alguns anos) sem mostrar algum tipo 
$\overline{\text { de impacto, como o desaparecimento de nascentes e cursos d'água, morte maciça da }}$ ictiofauna (peixes), de plantas hidrófitas (que vivem na água) e higrófitas (que vivem na dependência de ambientes muito úmidos), aumento na incidência de incêndios florestais etc.

Outros dois fatos históricos muito requisitados na literatura referem-se à derrota de Napoleão Bonaparte e, mais recentemente, durante a Segunda Guerra Mundial, do exército alemão, em investidas contra a Rússia. Segundo Acot (2005) o inverno extremamente frio dessa região teria imposto elevado número de baixas e forçado a retirada (e derrota) dos exércitos invasores. Entretanto, conforme comenta o autor, os russos também estavam expostos ao mesmo frio que afligia os franceses e alemães e, no entanto, em vez de recuar, a partir de certo momento avançaram sobre os territórios outrora sob domínio dos invasores. Neste caso, nota-se que o povo russo estava melhor aparelhado cultural e tecnologicamente para resistir ao frio.

As secas no nordeste brasileiro como causa do relativo atraso social e econômico dessa região também constam do rol das falácias climatológicas. Monteiro (1999), com toda razão, atribui esse fato à arcaica estrutura política e social nordestina, herança do período colonial. O "coronel”, mandatário e grande proprietário de terras, atuaria como uma espécie de senhor feudal exercendo controle coercitivo sobre segmentos da população e da política dos municípios e estados em seu favor.

Para verificar isso basta considerar o estado da Califórnia nos Estados Unidos da América, maior produtor agrícola desse país, onde os totais da chuva giram ao redor de $250 \mathrm{~mm} / \mathrm{ano}$, no limite entre aridez e semi-aridez que, quando comparados aos do nordeste brasileiro, situados entre 350 e $600 \mathrm{~mm} / \mathrm{ano}$, torna esta região úmida perante aquela nos Estados Unidos. Diferentemente do Brasil, na Califórnia há amplos sistemas de captação de água de chuva, além de contar com usinas de dessalinização de água do mar em escala industrial. No nordeste brasileiro os sistemas de captação de água de chuva foram introduzidos recentemente e de forma muito restrita utilizando os telhados de casas muito simples e pequenas para captar água e conduzi-la a cisternas.

Evidentemente, há casos no qual a participação do clima coloca-se como fator preponderante. É o caso dos pequenos empreendimentos agrícolas e da agricultura de subsistência, totalmente dependente das condições climáticas naturais. Mesmo para a agricultura tecnificada (dotada de irrigação, plantas transgênicas mais resistentes a seca e pragas etc.), menos dependente das variações dos atributos climáticos, condições 
"óptimas" de temperatura e disponibilidade de água representam economia de dinheiro. O mesmo vale para áreas urbanas nas quais, se bem aproveitado o recurso climático (ventilação natural, luz solar, sombreamento, água de chuva, umidade do ar etc.), gastos com acondicionamento de ambientes interiores seriam bastante reduzidos.

Diante dos argumentos cabem os seguintes questionamentos: a relativa falta de água constitui-se, de fato, numa "crise hídrica"? Quais suas reais causas e consequências? O que pode ser feito a respeito para solucionar o problema? As respostas a essas perguntas constituem-se no objetivo do presente artigo.

Parece contraditório, mas será possível "crise hídrica" no país de maior potencial hídrico do mundo? Isso, evidentemente, leva a pensar como causa dessa "crise" o despreparo dos governos estaduais para soluções de problemas de médio e longo prazo relativos à captação, armazenamento, tratamento e distribuição de água potável no Brasil, uma vez que as empresas de administração dos recursos hídricos são de competência dos estados e, mais do que isso, não se trata de um acontecimento novo, já que o episódio do "apagão", vivenciado pelo brasileiro entre os anos 2001 e 2002 trouxe a tona várias questões que já deveriam ter sido resolvidas a fim de evitar outras "crises" como a que acontece no momento.

\section{PROCEDIMENTOS METODOLÓGICOS E BREVE REVISÃO DO ASSUNTO}

A análise acerca do assunto foi pautada na revisão de algumas leituras, discutidas ao longo do todo o texto, ao redor de aspectos teóricos do clima enquanto sistema complexo, em matérias de cunho jornalístico sobre o tema em pauta, bem como da utilização de dados de clima oriundos de séries temporais de dados meteorológicos a fim de conferir suporte a vários dos argumentos elencados.

A bibliografia a respeito é vasta, principalmente no tocante aos aspectos teóricos da hidrologia, impactos ambientais, e a relação "clima e sociedade". E tem sido ampliada continuamente, inclusive com textos jornalísticos.

A legislação brasileira por meio da Resolução CONAMA no. 001 de 23 de janeiro de 1986 define impacto ambiental como: "qualquer alteração das propriedades físicas, químicas e biológicas do meio ambiente, causada por qualquer forma de matéria ou energia resultante das atividades humanas que, direta ou indiretamente, afetam: I - a saúde, a segurança e o bem-estar da população; II - as atividades sociais e econômicas; 
$\overline{\text { III - a biota; IV - as condições estéticas e sanitárias do meio ambiente; V - a qualidade }}$ dos recursos ambientais". Embora a natureza também produza impactos (danos decorrentes de erupções vulcânicas, terremotos, tsunamis etc.), deve-se atentar para o fato de que a resolução inclui como causa a "ação humana".

O conceito de "sistema" constitui-se num ponto de partida para compreensão das organizações naturais e humanas, já que insere o objeto de estudo num sistema de relações (entre diferentes objetos, de fluxos de matéria e energia, hierarquia, propriedades emergentes etc.). Autores como Drew (1986) e Christofoletti (1979; 1999) tratam a questão de forma pormenorizada ao caracterizar os sistemas naturais. Deve-se tomar o cuidado, no entanto, que, como qualquer modelo explicativo, a necessária simplificação para compreensão do todo implica na supressão de aspectos importantes dos objetos. Como acontece na questão relativa às mudanças climáticas, reduziu-se toda a compreensão do clima às variações de carbono atmosférico: mais gás carbônico presente na atmosfera significaria, supostamente, maior disponibilidade de calor, uma vez que esse gás interage com uma fatia dessa radiação (calor). A partir dessa relação foi deduzido todo um universo de possíveis acontecimentos (normalmente ligados a catástrofes). Neste caso atribuiu-se à compreensão de um sistema extremamente complexo uma explicação extremamente simples, ao nível intelectual de crianças de seis ou sete anos.

No que diz respeito à climatologia, um importante tópico refere-se à articulação entre ambiente natural e as sociedades humanas, escopo dos estudos geográficos, aproveitados neste artigo. Roseghini (2007, p.25), citando Silva Batista e Sant'Anna Neto (2005), define melhor a natureza do clima ao abordar os "eventos extremos": "A ocorrência de eventos climáticos extremos não obedece a uma ciclicidade de acontecimentos. Seu caráter irregular faz com que tenhamos conta de como a sucessão dos estados médios da atmosfera oscila, provocando os ditos acidentes ou "azares" climáticos aos mais variados espaços" e ainda "se o espaço pode ser consumido por agentes sociais desiguais, a produção dos mesmos também se dará de forma desigual".

Dependendo das características do espaço e da sociedade que o habita, um dado evento tanto pode ser atenuado quanto intensificado. Sociedades melhor organizadas do ponto de vista econômico, político e ambiental, como o Japão e o Chile, possuem melhores condições do que o Haiti de absorver impactos como aqueles provocados por terremotos, conforme denunciam episódios recentes dessa natureza. Além do mais, 
eventos não previstos da magnitude de catástrofes também fazem parte da evolução dos ambientes naturais.

\section{RESULTADOS}

Como pode ser visto os problemas aqui abordados não se constitui em novidade, alguns deles já amplamente discutidos no conhecido episódio da "crise do apagão" entre os anos 2001 e 2002. Naquela ocasião houve necessidade de racionar o consumo de energia elétrica, do qual o povo brasileiro participaria de forma voluntária e efetiva, acompanhados de "blecautes" ou "cortes programados" de energia em grande parte do país. Não é preciso lembrar que as perdas em termos de economia somaram bilhões de reais que, segundo auditoria do TCU (Tribunal de Contas da União), gerou prejuízo ao Tesouro de 45,2 bilhões de reais (http://pt.wikipedia.org/wiki/Crise_do_apagão), exigindo, mais uma vez, a participação de toda a sociedade brasileira na restituição desse prejuízo na forma de aumento nas tarifas de energia.

Inicialmente a culpa recaiu nas condições climáticas daquela época, uma vez que os totais de chuva em diversas regiões brasileiras (exceto na região sul) ficaram abaixo da média, implicando na diminuição do volume da água dos reservatórios. E como o fornecimento de energia elétrica no país apoiava-se (e esse quadro não mudou muito) na hidroeletricidade (superior a 90\% àquela época contra aprox. $70 \%$ atualmente), variações importantes nos totais de chuva podem repercutir nesse sistema. Conclui-se, portanto, que a causa está na limitada diversificação e na falta de investimento de ampliação do parque fornecedor de energia elétrica, o que torna esse sistema vulnerável à pressão de outros fatores, como a diminuição dos totais de chuva.

Outro aspecto que não pode ser descartado naquela ocasião foi a privatização das companhias distribuidoras de eletricidade e de água, que volta à tona nos dias de hoje. A suposta incapacidade das companhias estatais em suprir a demanda energética e de água no Brasil foi utilizada como argumento para as privatizações. Betto (2014) cita na revista "Caros Amigos" o valor de 33 reais o Megawatt-hora (MW/h) gerado pelas estatais federais contra 822,83 reais gerado pelas companhias de economias mistas e privadas. Embora os preços tenham aumentado o problema não foi solucionado e a ameaça de "apagões" continua sondando os brasileiros nos dias de hoje. Neste caso, a quem de fato atendeu as privatizações? 
A fim de esconder as verdadeiras causas do problema, é muito mais fácil atribuir culpa a fenômenos de explicações questionáveis e/ou impossíveis de provar, como certas previsões do clima para daqui a cem anos como constam dos relatórios do Painel Intergovernamental Sobre Mudanças do Clima (IPCC), do que avaliar os fatos. E o que é fato ao se tratar da suposta "crise hídrica?

De fato há uma crise, embora esta pouco ou nada tenha a ver com a falta ou diminuição dos totais de chuvas. Apostar no clima significa apostar no acaso e, como qualquer sistema complexo, os vários elementos climáticos (temperatura, umidade do ar, pressão, ventos, chuvas etc.) oscilam enormemente em termos de escala espacial (repercussões nas diferentes localidades) e temporal (horária, diária, mensal, anual, decadal etc.) sendo que a análise dos dados de uma série histórica de dados meteorológicos permite verificar isso.

(1) Fatos climáticos. Uma vez que se trata de um sistema complexo, a atmosfera terrestre, juntamente às demais "esferas" (litosfera, hidrosfera, biosfera etc.), formam um complexo de interações cujo resultado é a imensa diversidade de ambientes. E, como uma das principais características desse tipo de sistema, o clima inclui a presença de vários componentes caóticos, embora não se constitua num sistema essencialmente caótico. Caso assim fosse Belo Horizonte poderia registrar $5,0^{\circ} \mathrm{C}$ negativos em pleno verão e no dia seguinte valores de temperatura superiores aos $35,0^{\circ} \mathrm{C}$ positivos. Embora não haja série de dados suficientes que permita descartar uma situação extrema desse tipo, é altamente improvável (mas não impossível) que isso aconteça considerando o conhecimento acumulado até o momento. Por outro lado o clima encerra, também, componentes típicos de sistemas regulares, como certos fenômenos cíclicos como a sucessão dos dias e noites, das estações do ano, da maior ou menor recorrência de certos eventos ligados à chuva e variações de temperatura em determinados períodos no decorrer do ano etc., que é justamente o que torna possível o planejamento agrícola, por exemplo.

É evidente que o bom profissional agrônomo está atento aos "desvios" na variação dos elementos do clima (relativos àqueles componentes caóticos já mencionados), o que permite a ele estimar as perdas e, assim, avaliar a viabilidade econômica do empreendimento. Não apenas o agrônomo, mas todos aqueles que utilizam direta ou indiretamente dados de clima deveriam estar atentos a isso, o que 
inclui a administração pública (municipal, estadual e federal) no que diz respeito ao planejamento dos recursos hídricos em médio e longo prazo.

Apenas a título de exemplo, podem ser observadas na figura 01 as variações da chuva no decorrer dos anos para a localidade de Belo Horizonte (Estação Belo Horizonte, região central da capital; Lat.: 1956' S; Long.: 4356' W; Alt.: 850 m). O valor médio dessa série (de 1961 a 2013) corresponde a 1536,3 mm/ano. Em vários momentos é possível observar os desvios em relação à média, notadamente nos anos de 1962 (1984,9 mm), 1963 (497 mm), 1970 (1129 mm), 1981 (1084,2 mm), 1983 (2307 mm), 1990 (1039,6 mm), 2004 (1936,8 mm), 2008 (2024,7 mm), 2009 (2151,5 mm) e $2011(2026,2 \mathrm{~mm})$.

Em alguns anos como fica claro o total de chuva superou os $2000 \mathrm{~mm}$ e em outro momento ficou abaixo de $500 \mathrm{~mm}$. É evidente que há impactos associados a essas variações e podem variar desde enchentes, perdas agrícolas, racionamento de água etc. Entretanto, essas variações são perfeitamente "normais" e incluem-se naquilo que a climatologia denomina por "variabilidade climática" e não "mudança climática". A "pequena idade do gelo" que perdurou entre os séculos 13 e 19 e os ciclos de glaciações são exemplos verdadeiros de mudanças climáticas e abrangem períodos de vários séculos a dezenas de milhares de anos. Ou seja, através das séries temporais disponíveis, com pouco mais de cem anos de dados, é impossível verificar alguma mudança persistente de longa data. A "variabilidade climática", de acordo com Steinke (2004, p.13), apoiada em Conti (2000), refere-se a "maneira pela qual os parâmetros climáticos variam no interior de um determinado período de registro expresso através de desvio padrão ou coeficiente de variação". Diferentemente das mudanças climáticas, a variabilidade abrange períodos de anos e décadas e é influenciada por fenômenos como atividade solar, aquecimento e resfriamento dos oceanos, El Niño etc., todos de abrangência temporal similar. 


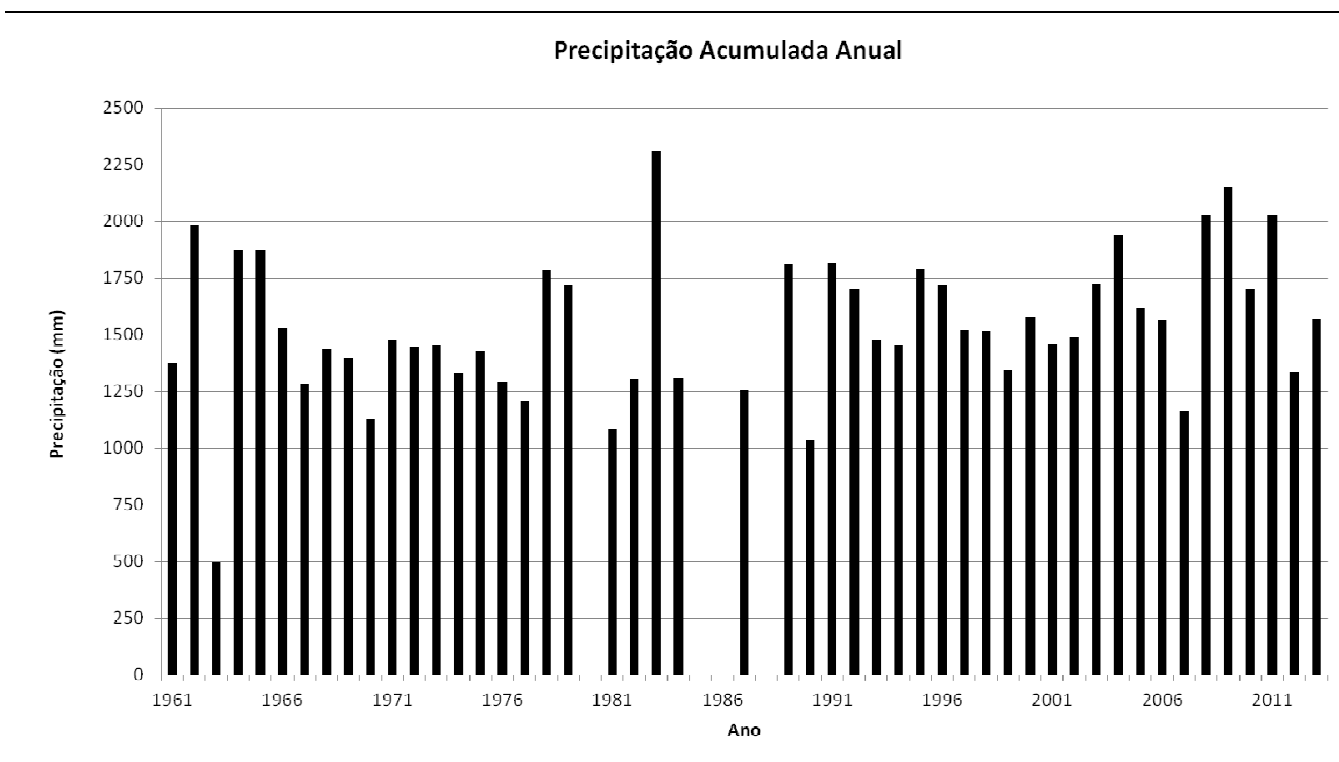

Fig. 01. Dados anuais de chuva em Belo Horizonte-MG: série de 1961 - 2013 (Fonte: www.ana.gov.br).

(2) Falta de água versus potencial hídrico. A atual "crise hídrica" revela a clara contradição entre a realidade do país detentor do maior potencial hídrico do mundo e a falta de água (somente a descarga do Amazonas responde por $20 \%$ da água doce que deságua nos oceanos do mundo inteiro). Excluindo o semiárido (onde há de fato déficit hídrico) e breves períodos de seca no sudeste e centro-oeste do Brasil, todas as demais regiões brasileiras apresentam excedente hídrico no decorrer do ano. Tal fato permite, inclusive, discussões acerca de projetos de transposição de águas entre os estados e regiões. Se há excedente em alguns lugares por que não levá-lo para lugares onde há déficit hídrico? A questão importante, neste caso, é debater a quem esse recurso estará disponível: para toda a população ou apenas para alguns setores historicamente privilegiados como o agronegócio?

(3) Necessidade de diversificar e ampliar o parque nacional de produção de energia elétrica, hoje (ainda) concentrada na hidroeletricidade, juntamente com a ampliação da rede de captação, armazenamento e distribuição de água, incluíndo formas alternativas de aproveitamento de águas de chuva, dessalinização da água do mar etc. As hidrelétricas, e os reservatórios d'água que as alimentam, são obras necessárias, sem dúvida, enquadrando-se no rol das formas de energias renováveis. Entretanto, novos investimentos devem ser feitos para melhor aproveitamento das áreas inundadas pelas 
$\overline{\text { represas. Além de extraordinariamente caras o impacto gerado é imenso e reflete-se em }}$ vários níveis de organização social e ecológica. Pode-se citar como exemplo a remoção das populações ribeirinhas, desaparecimento de espécies de anfíbios e de parte da ictiofauna de água corrente em detrimento de espécies oportunistas e típicas de ecossistemas lacustres, morte de animais e destruição florestas decorrente do afogamento dos vales (que pode levar à alterações nas características físico-químicas da água), mudanças no padrão de sedimentação, implicando na retração de deltas e estuários e imposição da dinâmica costeira nesses setores etc.

A represa Billings, instalada ao sul do município de São Paulo, criada na década de 1930-40, com o objetivo de atender a demanda por água da usina hidrelétrica Henry Borden para fornecer energia elétrica ao pólo petroquímico de Cubatão, poderia atender, também, a quase totalidade das necessidades de água potável da cidade de São Paulo. Mas isso não acontece, pois a água que a alimenta é proveniente das bacias do Alto Tietê, revertidas através do rio Pinheiros, que é um imenso esgoto a seu aberto. Para fornecimento de energia elétrica, não importa se a água é poluída ou não, mas para fornecimento de água potável a mesma teria que ser tratada, o que não acontece adequadamente, pois apenas dois de seus trechos possuem condições para aproveitamento no abastecimento de água potável.

(4) As populações das áreas urbanas não são as únicas nem as principais usuárias dos sistemas hídricos. Sendo assim, por que é justamente sobre elas que recai o ônus pela má utilização desse recurso, através da aplicação de sobretaxas de consumo d'água como quer o governo Alkimin no estado de São Paulo e como aconteceu no episódio do "apagão" com aumento das taxas de energia elétrica? De acordo com dados do World Water Assessment Programme (2003) nos países subdesenvolvidos e em desenvolvimento, como é o caso do Brasil, o setor agropecuário (irrigação, dessedentação de animais etc.) consome em torno de $82 \%$ da água disponível, a indústria fica com $10 \%$ e o restante, $8 \%$, para uso doméstico. Essas cifras, no âmbito mundial, equivalem, respectivamente, a $70 \%, 22 \%$ e $8 \%$.

(5) Necessidade de planejamento de médio e longo prazo. É evidente que há medidas emergenciais que necessitam de resolução imediata. Certos programas sociais de governo ("Fome Zero", cotas nas universidades, bolsa família etc.) são extremamente importantes, mas não podem substituir programas efetivos de médio e longo prazo, como a ampliação do acesso e melhoria da qualidade dos serviços públicos (que é, 
também, a melhor forma de distribuição de renda). A resolução de problemas emergenciais confere visibilidade ao governo e, por extensão, àqueles que ocupam certos cargos na administração pública, mas medidas de médio e longo prazo exigem a elaboração de planejamento, ou seja, de disciplina no uso do dinheiro público a fim de minimizar gastos não prioritários.

Localidades afligidas por enchentes, escorregamentos de solo, incêndios florestais, contaminação de cursos d'água etc. requerem, muitas vezes, atenção imediata. Episódios desse tipo constituem-se em acidentes e, portanto, imprevisíveis, mesmo nas sociedades mais organizadas. Entretanto, ao mesmo tempo, como medida de médio e longo prazo, deve-se pensar na implantação de mecanismos para minimizar os efeitos desses eventos no futuro, poupando recursos do orçamento para outros fins.

Esse mesmo raciocínio deveria ter sido aplicado à questão do abastecimento hídrico. A indústria brasileira, o agronegócio, a agricultura familiar, o setor de prestação de serviços e a própria população brasileira etc. aumentaram desde o "apagão" de 20012002, e todos utilizam, em maior ou menor proporção, elevadas quantidades de água. Será que esse dado não consta do planejamento das administrações públicas estaduais? Ou não há planejamento? Ou há planejamento e o mesmo não é cumprido?

De acordo Avellar et al. (2015) a partir de dados do IPEA e IBGE, a população cresceu de 169.799.170 habitantes no ano de 2000 para 190.755.799 habitantes em 2010; a expectativa de vida subiu de 70,14 para 73,1 ; nesse mesmo período o PIB cresceu de 644 bilhões para 2,1 trilhões de dólares. Até mesmo semanários de grande tiragem e alcance nacional como a revista "Veja", trazem dados dessa natureza. Em matéria de Costa (2015) veiculada em 14/03/2013 sobre o crescimento econômico dos países emergentes, a partir de dados do Relatório de Desenvolvimento Humano (RDH) do Programa das Nações Unidas para o Desenvolvimento (Pnud) de 2013 constata-se o seguinte:

\footnotetext{
A pesquisa cita o Brasil, a China e a Índia como os principais motores de tal desenvolvimento nos últimos anos. Segundo o Pnud, a China reduziu seu déficit de Índice de Desenvolvimento Humano (IDH) mais que qualquer outro país do globo. Já o Brasil e a Índia colheram frutos de programas de transferência de renda e incentivo ao emprego. Em 1950, diz o relatório, os três países representavam não mais que $10 \%$ do Produto Interno Buto (PIB) mundial. Em 2050, o Pnud prevê que essas nações correspondam a 40\% da geração de riqueza global. Isso significa que seu PIB conjunto será maior do que a soma das economias da Alemanha, da Grã-Bretanha, da França, da Itália, do Canadá e dos Estados Unidos. Tal avanço econômico será liderado,
} 
sobretudo, por parcerias tecnológicas entre as próprias nações em desenvolvimento, de acordo com o levantamento.

Em outra reportagem da mesma revista de Tuon (2015) veiculada em 12/03/2013: "Em 2011, 61 das 500 maiores corporações do mundo que entraram na lista da revista Fortune eram chinesas, oito eram indianas e sete brasileiras. Apenas cinco anos antes, a China tinha 16 empresas na lista, a Índia, cinco, e o Brasil, três”. Ou seja, na relação de compra de empresas sediadas em países desenvolvidos por países emergentes, fica claro o crescimento econômico destes últimos.

Esse raciocínio de médio e longo prazo também deve ser aplicado no sentido de prevenir impactos ambientais, não apenas em relação à água para o abastecimento da população, mas no caso de empreendimentos como o "mineroduto" da empresa Anglo American, para transporte de minério de ferro, atravessando 32 municípios entre os estados de Minas Gerais e Rio de Janeiro. Em matéria datada de 24/09/2013 veiculada no jornal "O Tempo" de Pedrosa e Ariadne (2015) alguns aspectos dessa questão são esclarecidos:

\begin{abstract}
A crise hídrica, que ameaça o abastecimento de água e energia do país, também não impediu o licenciamento. Para funcionar, o empreendimento vai precisar de 2,5 milhões de litros de água por hora. A outorga para a captação já foi concedida pelo Instituto Mineiro de Gestão das Águas (Igam). A água sairá do rio do Peixe e é suficiente para abastecer cerca de 393 mil pessoas, o equivalente à população de Montes Claros, no Norte de Minas. O cálculo leva em consideração o consumo de 152,6 litros por dia para cada habitante. Esse foi o consumo médio do país nos últimos três anos, de acordo com o Sistema Nacional de Informações sobre o Saneamento (Snis), publicado pelo Ministério das Cidades [...] No fim de agosto foi registrada uma mortandade de peixes no córrego Passa Sete, em Conceição do Mato Dentro. O fato ocorreu dias após a Anglo American realizar o primeiro carregamento no Minas-Rio, como teste. De acordo com o procurador do Ministério Público Federal (MPF), Helder Magno da Silva, a causa do problema não foi apurada pelo Ibama antes da concessão da licença ao empreendimento. "Não tem nenhum fato que pudesse causar essa mortalidade que não seja uma contaminação decorrente do empreendimento", afirma.
\end{abstract}

Por que não se optou pela melhoria e ampliação da rede ferroviária para transportar o minério? Neste caso cabem duas alternativas a saber: (1) a água é considerada um recurso abundante e barato a ponto de substituir as ferrovias e, portanto, não há crise hídrica ou (2) outros segmentos da sociedade terão de arcar com o ônus desse empreendimento como já aconteceu no episódio do "apagão" com o aumento no 
valor das taxas de consumo de energia elétrica (e, neste caso, no aumento do valor das taxas de consumo de água).

\section{CONSIDERAÇÕES FINAIS}

Nota-se que dos pontos discutidos nenhum deles nunca foi efetivamente levado adiante e/ou encarado com seriedade pela administração pública e, conforme enfatiza o físico Paulo Artaxo da Universidade de São Paulo, em matéria veiculada pela revista “Caros Amigos” (PRIMI, 2014, p.16), “A crise da água em São Paulo é um problema de gestão". Mesmo que houvesse a possibilidade de prever a redução das chuvas, o que de fato aconteceu no ano de 2014 em relação à média climatológica, as medidas deveriam ter sido tomadas com antecedência de vários anos.

Giovanini (2015) em matéria veiculada pela internet datada de 31/01/2015 (“Crise Hídrica? Que crise? Não existe nenhuma crise hídrica!”) resume muito bem a atitude "imediatista" da administração pública brasileira em contraposição às necessárias decisões de médio e longo prazo:

[...] "A falta de água não é uma "crise" porque ela não será passageira. Os fatores que levaram ao esvaziamento das represas não cessarão subitamente. Recuperar as Matas Ciliares que protegem os rios do assoreamento, reflorestar grandes áreas para manter a perenidade das nascentes, cessar o desmatamento da Mata Atlântica e da Amazônia, substituir uma prática agrícola predatória e, principalmente, adotar um novo modelo de desenvolvimento, não são medidas fáceis de serem adotadas e muito menos elas se encontram presentes na agenda dos atuais governantes" [...] "Os reservatórios até poderão encher, mas as razões que os levaram a secar continuarão e eles novamente voltarão a ser o que são hoje: terra seca" [...] "O "Colapso Hídrico" se instalou porque esgotamos o atual modelo de desenvolvimento, que privilegia a distribuição de lucros em detrimento dos investimentos em pesquisa e conservação ambiental.".

Não é preciso ser especialista em meio ambiente para verificar a veracidade das afirmações acima. A recuperação das matas ciliares, bem como a preservação e recomposição de florestas em áreas de nascentes, a exemplos da Serra da Mantiqueira ao norte do município de São Paulo e da Serra do Gandarela, no Quadrilátero Ferrífero, a leste de Belo Horizonte, levaria décadas. Embora o tempo de regeneração das florestas seja extremamente variável, de acordo com Chazdon (2012) para florestas tropicais 
estima-se que pode levar mais de um século entre os estágios iniciais até o estabelecimento de floresta primária, ou seja, entre 0 a 15 anos com o início do povoamento, 15 a 50 anos para exclusão de espécies intolerantes à sombra, 30 a 200 anos para reinício do sub-bosque e superior a 200 anos para atingir o estágio de floresta madura.

Embora tenha sido declarada recentemente unidade de conservação na categoria de parque nacional (O que representa um avanço, sem dúvida!), constando entre os poucos redutos de mata preservada em todo o quadrilátero ferrífero, toda a área ao redor da Serra do Gandarela ainda é alvo de disputa por mineradoras como a Vale do Rio Doce, atraídas pela "canga ferruginosa" (minério de ferro). E sequer foi delimitada ao redor do recém-criado parque uma zona de amortecimento de impactos das áreas urbanas e agrícolas limítrofes.

Portanto, diante dos aspectos apontados, há que se rever uma série de encaminhamentos políticos, pensando na sociedade como um todo e não apenas em determinados segmentos dessa sociedade e/ou grupos econômicos poderosos que alimentam as campanhas políticas. Isso, evidentemente, inclui o ambiente, que é o suporte da sociedade, palco onde se estabelecem as relações sociais, assim como a divulgação de informações sérias calcadas em fatos e não em mitos como acontece no caso de uma suposta "mudança climática" induzida pela ação humana.

Que o ser humano possui capacidade de modificar o clima, isso é fato. Entretanto, essa capacidade não vai além de espaços microclimáticos. Alterações em amplos espaços regionais estão associadas a mecanismos de larga escala como a circulação geral atmosférica, correntes oceânicas, atividade solar etc. A suposta relação da "crise hídrica" no sudeste brasileiro com o desmatamento na Amazônia não passa de outra falácia pretensamente científica carente de quaisquer evidências. Não há necessidade de evocar mentiras para justificar a preservação de parte desse amplo espaço regional. A conservação da biodiversidade local, dos solos e das águas, bem como a defesa das populações que historicamente utilizam esse espaço constitui-se em motivos suficientes para sua conservação. 


\section{REFERÊNCIAS}

ACOT, P. Historia del clima: desde el big ban a las catastrofes climáticas. Buenos Aires: El Ateneo, 2005.

AVELLAR, P. R; GARCIA, E. G; SANTOS, C. S; crescimento econômico e desenvolvimento social no Brasil. Disponível em: <http://abresbrasil.org.br/sites/default/files/trabalho_11.pdf>. Data de acesso: $12 / 02 / 2015$.

BERLATO, M. A.; FONTANA, D. C. El Niño e La Niña: impactos no clima, na vegetação e na agricultura do Rio Grande do Sul; aplicações de previsões climáticas na agricultura. Porto Alegre: Editora da UFRGS, 2003.

BETTO, F. Energia a que preço? Caros Amigos, São Paulo, n.205, p.34, abr/2014.

COELHO, C. A. S.; CAVAlCANTI, ITO, E. R.; LUZ, G.; SANTOS, A. F.; NOBRE, C. A.; MARENGO, J. A.; PEZZA, A. B. As secas de 1998, 200532010 - Análise Climatológica. In: BORMA, L. S. \& NOBRE, C. A. Secas na Amazônia: Causas e consequências. São Paulo: Oficina de Textos, 2013, cap. 6, p. 89-116.

BRASIL. Agência Nacional de Águas (ANA). Disponibilidade e demandas de recursos hídricos no Brasil. Brasília: ANA, 2007. (Cadernos de Recursos Hídricos, 2).

CHAZDON, R. L., Regeneração de florestas tropicais. Boletim do Museu Paraense Emílio Goeldi. Ciências Naturais, Belém, v. 7, n. 3, p. 195-218, set.-dez/2012.

CONTI, J. B. Considerações sobre mudanças climáticas globais. IN: SANT'ANA NETO, J. L. e ZAVATINI, J. A. (org). Variabilidade e mudanças climáticas. Maringá: Eduem, 2000, p. 17 - 28.

COSTA, A. C. Emergentes conduzem crescimento econômico e social do mundo, aponta PNUD. Disponível em: <http://veja.abril.com.br/noticia/economia/emergentesconduzem-crescimento-economico-e-social-do-mundo-aponta-pnud>. Data de acesso: $15 / 02 / 2015$. 
DREW, D. Processos interativos homem - meio ambiente. São Paulo: Difusão Editorial, 1986.

CHRISTOFOLETTI, A. Análise de sistemas em geografia. São Paulo: Hucitec: Editora da Universidade de São Paulo, 1979.

CHRISTOFOLETTI, A. Modelagem de sistemas ambientais. 1.ed. São Paulo: Edgard Blücher, 1999.

DIAMOND, J. Colapso: como as sociedades escolhem o fracasso ou o sucesso. Rio de Janeiro: Record, 2005.

FAGAN, B. O aquecimento global: A influência do clima no apogeu e declínio das civilizações. São Paulo: Lorousse/Escala, 2009.

GIOVANINI, D. Crise Hídrica? Que crise? Não existe nenhuma crise hídrica! <http://sustentabilidade.estadao.com.br/blogs/dener-giovanini/crise-hidrica-que-crisenao-existe-nenhuma-crise-hidrica/> Data de acesso: 04/02/2015.

MONTEIRO, C. A. F. O estudo geográfico do clima. Cadernos Geográficos, Florianópolis, n.1, 1999.

PEDROSA, A. P; ARIADNE, Q. Mesmo com alertas da UFMG e MPF, Ibama libera mineroduto. Disponível em: <http://www.otempo.com.br/capa/economia/mesmo-comalertas-da-ufmg-e-mpf-ibama-libera-mineroduto-1.920839 >. Data de acesso: $12 / 02 / 2015$.

PRIMI, L. Impactos das mudanças climáticas: alterações no clima já influem nos recursos hídricos na América Latina e no regime de chuvas, o que pode mudar até a produção agrícola. Caros Amigos, São Paulo, n. 72, p.16-18, dez/2014.

ROSEGUINI, W. F. F. Ocorrência de eventos climáticos extremos e sua repercussão sócio-ambiental no litoral norte paulista. Dissertação (Mestrado em Geografia), Universidade Estadual Paulista - Faculdade de Ciências e Tecnologia, Presidente Prudente-SP, 2007.

STEINKE, E. T. Considerações sobre variabilidade e mudança climática no Distrito Federal, suas repercussões nos recursos hídricos e informação ao grande público. Tese (Doutorado), Departamento de Ecologia, Universidade de Brasília, Brasília-DF, 2004.

TUON, L. Emergentes compram mais empresas de países desenvolvidos. Disponível em: < http://veja.abril.com.br/noticia/economia/crescem-aquisicoes-de-empresas-feitaspor-paises-emergentes>. Data de acesso: 15/02/2015. 
WORLD WATER ASSESSMENT PROGRAMME. Water for People, Water for Life:

The United Nations World Water Development Report. Paris: UNESCO, 2003. 